\title{
ARRANJOS PRODUTIVOS LOCAIS E DESENVOLVIMENTO REGIONAL: DIAGNÓSTICO DOS APLS DA REGIÃO SUDOESTE DO PARANÁ
}

\author{
LOCAL CLUSTERS AND REGIONAL DEVELOPMENT \\ PRODUCTIVE: DIAGNOSIS OF APL IN THE SOUTHWEST \\ REGION OF PARANÁ
}

\author{
Alexandre Luiz Schlemper \\ Instituto Federal do Paraná/Câmpus Palmas - Palmas - PR - Brasil \\ Marcos Junior Marini \\ Universidade Tecnológica Federal do Paraná/Câmpus Pato Branco - Pato Branco - PR - \\ Brasil \\ Maria de Lourdes Bernartt \\ Universidade Tecnológica Federal do Paraná/Câmpus Pato Branco - Pato Branco - PR - \\ Brasil
}

\begin{abstract}
Resumo: As discussões da literatura apontam para uma mudança no sistema capitalista nas últimas décadas do século $X X$, principalmente devido à passagem do modo de produção em massa para um regime de especialização flexível, ocasionando a valorização das aglomerações produtivas locais como estratégia para o desenvolvimento regional. Nesse cenário, esta pesquisa objetivou realizar um diagnóstico setorial dos Arranjos Produtivos Locais - APLs da região Sudoeste do Paraná, visando orientar a elaboração de estratégias de desenvolvimento. Como encaminhamento metodológico, optou-se pela aplicação da metodologia Strengths (forças), Weaknesses (fraquezas), Opportunities (oportunidades) e Threats (ameaças) - SWOT para a compilação dos resultados da pesquisa de campo, gerando um conjunto de apontamentos em relação às forças, às fraquezas, às oportunidades e às ameaças nos APLs analisados. Os resultados demonstraram a relevância desta pesquisa para a definição de estratégias e políticas públicas relacionadas ao desenvolvimento destes APLs e da respectiva região.
\end{abstract}

Palavras-chave: Arranjos Produtivos Locais. Desenvolvimento regional. Sudoeste do Paraná. Metodologia SWOT. Diagnóstico sectorial. Políticas públicas.

Abstract: Discussions of literature point to a change in the capitalist system in the last decades of the twentieth century, mainly due to the passage of the mode mass production for a system of flexible specialization, leading to clusters as a strategy for regional development. In this scenario, this research aimed to conduct a sector analysis of the clusters from southwestern of Paraná, order to guide the elaboration of development strategies. The guiding methodological occurred with the application of the SWOT methodology for the compilation of the results of field research, generating a set of notes regarding the strengths, weaknesses, opportunities and threats in the clusters analyzed. The results demonstrated the relevance of this research for the development of strategies and policies related to the development of these clusters and their region.

Keywords: Clusters. Regional development. Southwest of Paraná. SWOT methodology. Sector analysis. Public policies. 


\section{INTRODUÇÃO}

As discussões da literatura apontam para uma importante mudança no sistema capitalista mundial nas últimas décadas do século $X X$, com a passagem do sistema de produção em massa para o regime de especialização flexível (ALBUQUERQUE, 1998; BENKO, 1999; LASTRES, CASSIOLATO E ARROIO; 2005).

Nesse contexto, caracterizado por indústrias menos verticalizadas, surgem novas perspectivas de produção, originando ainda uma reestruturação espacial da sociedade, com a valorização das questões territoriais e de suas aglomerações industriais (ALBUQUERQUE, 1998; BENKO, 1999). Adicionalmente, são necessárias políticas públicas que considerem as condições locais, nacionais e internacionais para as questões do desenvolvimento.

Corroborando com este debate, Lastres e Cassiolato (2003) alertam que nesse novo cenário mundial, o foco na empresa individual se transfere para as relações entre empresas e o conjunto de instituições presentes em um espaço geográfico local ou regional. Ademais, a inovação passa a ser um elemento central para esta dinâmica (FREEMAN, 2005). Logo, observa-se que o aprendizado e o capital social também correspondem a elementos fundamentais para as estratégias de desenvolvimento.

É importante ressaltar ainda que todas essas discussões estão presentes nas chamadas Teorias do Desenvolvimento Econômico Endógeno, as quais se originaram na década de 1980, principalmente a partir de alguns casos de sucesso de aglomerações industriais, como os clássicos exemplos da Terceira Itália e do Vale do Silício nos Estados Unidos (ALBUQUERQUE, 1998; BENKO, 1999; LASTRES E CASSIOLATO, 2003).

Diante do exposto, observa-se a formação de um cenário que valoriza as aglomerações produtivas locais, tornando-as objeto de inúmeras pesquisas e estudos, bem como a inserção destas discussões nas políticas públicas de desenvolvimento local ou regional (SUZIGAN, 2006). Nesse sentido, esta pesquisa objetiva realizar um diagnóstico setorial dos arranjos produtivos locais existentes na região Sudoeste do Paraná, visando orientar a elaboração de estratégias de desenvolvimento, tanto para estes APLS como para o desenvolvimento desta região.

\section{Arranjos Produtivos Locais: contextualização e características}

Inicialmente, é importante ressaltar que os diversos estudos e vertentes teóricas inseridas nas discussões sobre o desenvolvimento econômico endógeno, originaram uma proliferação de terminologias para a caracterização das aglomerações produtivas locais, entre as quais: aglomerações industriais, distritos industriais, tecnopolos, milieux innovateurs (meios inovadores), sistemas produtivos locais, sistemas locais de produção, clusters, arranjos produtivos locais.

Nesse cenário, destaca-se que o termo APLs surgiu nas discussões realizadas no âmbito do Ministério de Ciência e Tecnologia - MCT do Brasil, no final da década de 1990, em uma tentativa de conceituar este fenômeno (COSTA, 2010). Logo, optou-se pela utilização dessa terminologia para as discussões propostas neste artigo. 
Em continuidade, cabe destacar que mesmo com a intensificação das discussões sobre as aglomerações produtivas locais a partir das últimas décadas do século $X X$, a literatura aponta para os estudos clássicos de Alfred Marshall envolvendo os distritos industriais de cutelaria na Inglaterra, no final do século XIX, como os precursores das discussões sobre a importância da concentração espacial de empresas. Nesse sentido, Marshall indicou a presença de economias externas (externalidades) como vantagens oriundas desse processo aglomerativo. Para esse autor,

Podemos dividir as economias derivadas de um aumento da escala de
produção de qualquer espécie de bens em duas classes: primeira, as
dependentes do desenvolvimento geral da indústria; e segunda, as
dependentes dos recursos das empresas que a ela se dedicam
individualmente, das suas organizações e eficiência de suas
administrações. Podemos chamar as primeiras de economias externas, e
as últimas de economias internas. (MARSHALL, 1982, p, 229, grifos do
autor).

Ainda nesses apontamentos, Marshall (1982) indica três principais economias de aglomeração, ou seja, as conhecidas externalidades marshallianas, a saber: um conjunto de trabalhadores qualificados para a atividade econômica; maior acesso aos fornecedores; e a rápida disseminação de novos conhecimentos.

Nesse debate, Garcia e Costa (2005) apontam para quatro formas de aglomerações produtivas que possuem suas bases nos distritos marshallianos: Polo de Crescimento (presença de uma grande empresa centralizadora cercada por uma cadeia de pequenas empresas de fornecimento e apoio, formando um polo industrial); Cadeia Produtiva (segmento com alta divisão do trabalho, gerando interdependência entre pequenas empresas); Milieux Innovateurs (ênfase na relação das empresas com o seu respectivo ambiente, o qual propicia a inovação coletiva); Clusters (a rivalidade dentro do aglomerado é vista como principal estímulo para o aumento de produtividade, inovação e desenvolvimento de novos negócios).

Corroborando com essas discussões, Becattini (1994) baseou-se nas experiências dos distritos industriais italianos (Terceira Itália) para apontar uma nova experiência de concentração territorial e cooperação das pequenas empresas, a qual inclui não somente as questões econômicas, mas também elementos presentes nas dimensões culturais, sociais e históricas daquele território. Segundo esse autor,

O distrito é uma entidade sócio-territorial caracterizada pela presença ativa de uma comunidade de pessoas e de uma população de empresas num determinado espaço geográfico e histórico. No distrito, ao invés do que acontece em outros tipos de meios, como por exemplo, as cidades industriais, tende a criar-se uma osmose perfeita entre a comunidade local e as empresas (Becattini, 1994, p. 20).

Dessa forma, o distrito industrial é visto como uma das vertentes dos distritos marshallianos, contudo, esse autor explicita a importância das questões territoriais como meio propulsor para a dinâmica industrial.

Outra vertente de análise das aglomerações produtivas é creditada a Michel Porter, o qual se tornou referência nos estudos sobre a competitividade existente nestes agrupamentos industriais, denominados cluster. Para esse autor, um cluster 
corresponde a "um conjunto de empresas independentes e informalmente ligadas a instituições. Representa uma forma robusta organizacional que oferece vantagens em termos de eficiência e flexibilidade". (PORTER, 1998, p.3). Portanto, evidencia-se que o elemento essencial para um cluster é o potencial competitivo e coletivo de seus agentes econômicos e sociais, gerando uma dinâmica que possibilita ganhos de produtividade (AMATO NETO, 2009).

Com relação à terminologia adotada no Brasil APLs, observa-se uma aproximação dos conceitos anteriores, incluindo também a importância das relações sociais entre o conjunto de agentes presentes nesse ambiente produtivo. De forma geral, APLs podem ser conceituados como:

\begin{abstract}
Aglomerados territoriais de agentes econômicos, políticos e sociais, com foco em um conjunto especifico de atividades econômicas, que apresentam vínculos mesmo que incipientes. Geralmente envolvem a participação e a interação de empresas, que podem ser desde produtoras de bens e serviços finais até fornecedoras de insumos e equipamentos, prestadoras e consultoria e serviços, comercializadoras, clientes e outros, e suas variadas formas de representação e associação. Incluem também diversas outras instituições públicas e privadas voltadas para: formação e capacitação de recursos humanos (como escolas técnicas e universidades); pesquisa, desenvolvimento e engenharia; política, promoção e financiamento. (LASTRES E CASSIOLATO, 2003, p. 27).
\end{abstract}

A partir desse conceito, é possível extrair algumas características importantes e necessárias para a existência de um $A P L$, entre as quais: é uma concentração territorial de empresas com especialidade produtiva; possui um conjunto de agentes de apoio (econômicos, sociais e políticos); apresenta vínculos interativos e a ocorrência de práticas cooperativas (ações conjuntas).

Ainda nessas discussões sobre APLs, Suzigan et al. (2004) apresentam uma proposta de tipologia para a classificação desses arranjos produtivos a partir do enquadramento em dois eixos principais: importância espacial (local ou regional) e importância para o respectivo setor. Logo, propõem a seguinte classificação: Embrião de Sistema Local de Produção (E), Vetor de Desenvolvimento Local (VDL), Vetor Avançado (VA) e Núcleo de Desenvolvimento Setorial-Regional (NDSR).

A proposta de Suzigan classifica as aglomerações produtivas espaciais, desde uma condição embrionária, onde o segmento possui ainda uma baixa representatividade tanto dentro do setor como na economia local, até um vetor que une a importância setorial dessa atividade econômica com a importância para o desenvolvimento local. O Quadro 1 apresenta os respectivos enquadramentos adotados nessa classificação (tipologia das aglomerações produtivas).

Quadro 1 - Tipologia das Aglomerações Produtivas

\begin{tabular}{|c|c|c|c|}
\hline & \multicolumn{2}{|c|}{ Importância para o Setor } \\
\hline & & Reduzida & Elevada \\
\hline \multirow{2}{*}{$\begin{array}{l}\text { Importância } \\
\text { Local }\end{array}$} & Elevada & $\begin{array}{c}\text { Vetor de Desenvolvimento } \\
\text { Local } \\
\text { (VDL) }\end{array}$ & $\begin{array}{l}\text { Núcleo de Desenvolvimento } \\
\text { Setorial-Regional } \\
\text { (NDSR) }\end{array}$ \\
\hline & Reduzida & $\begin{array}{l}\text { Embrião de Sistema Local de } \\
\text { Produção } \\
\text { (E) }\end{array}$ & $\begin{array}{c}\text { Vetor Avançado } \\
\text { (VA) }\end{array}$ \\
\hline
\end{tabular}

Fonte: Suzigan et al (2004). 
Uma vez apresentados os aspectos conceituais e de definição dos arranjos produtivos locais, é importante fazer alguns apontamentos sobre seu papel no processo de desenvolvimento regional. Para Dias (2011), os APLs proporcionam a possibilidade de proximidade física das empresas, estreitando os laços de confiança e cooperação e, consequentemente, ganho de competitividade, potencializando seus resultados e refletindo em distribuição de renda regional.

Teixeira (2008) alerta que um dos grandes problemas que os APLs brasileiros têm enfrentado hoje estão ligados a questão da gestão de governança dos mesmos, tanto em termos de falta de conhecimento conceitual, como também de gestão de conflitos. Assim, a possibilidade de produção de externalidades positivas regionais fica comprometida.

Para Costa (2010), os APLS podem, sim, desencadear e levar ao desenvolvimento regional, no entanto, é necessário que o APL esteja consolidado, o que para o autor, significa:

\begin{abstract}
...desenvolvimento das vocações microrregionais; agregação de valor aos produtos e verticalização da produção; diversificação da base produtiva e da pauta de exportação; avanço no indicador de inclusão social através da melhoria da qualidade do emprego, melhoria salarial, melhoria da qualificação técnica da mão de obra, e consequente diminuição da desigualdade social; aumento do mercado interno regional; gestação de um processo sustentado de crescimento por meio da endogeneização de algumas das variáveis-chaves, da integração do espaço econômico regional e do apoio às mudanças na estrutura sócioeconômica regional; e, desenvolvimento do capital social, da capacidade de governança dos agentes locais e do fomento à construção de um pacto territorial com vista ao desenvolvimento.(COSTA, 2010, pg 165).
\end{abstract}

Marini e Silva (2012) trazem uma abordagem sobre os APLs enquanto instrumentos não só para o desenvolvimento regional, mas para o desenvolvimento regional sustentável. Para tal, apontam que há a necessidade de compreender e estimular as inter-relações territoriais a partir de uma visão integrada sistêmica sob uma análise multidimensional. Essas dimensões seriam: social, econômica, ambiental, espacial, cultural, política e institucional.

Neste trabalho, será utilizada uma metodologia de análise ambiental conhecida como SWOT. Strengths (forças), Weaknesses (fraquezas), Opportunities (oportunidades) e Threats (ameaças). É um método de diagnóstico utilizado frequentemente na elaboração de planejamento estratégico. Apesar de não haver um consenso sobre sua origem, segundo Friesner (2014), a SWOT surge no início da década de 1950 com os professores George Albert Smith Jr e C Roland Christiensen da Universidade de Harward.

Atualmente, o método é largamente utilizado no meio coorporativo e de gestão estratégica e abordado por autores como, Porter (2009), Kotler e Armstrong (1998), Kaplan e Norton (1997), Certo e Peter (2010) e Mintzberg e Quinn (2001). A figura 1 representa a metodologia SWOT. 
Figura 1. Metodologia de Diagnóstico - SWOT

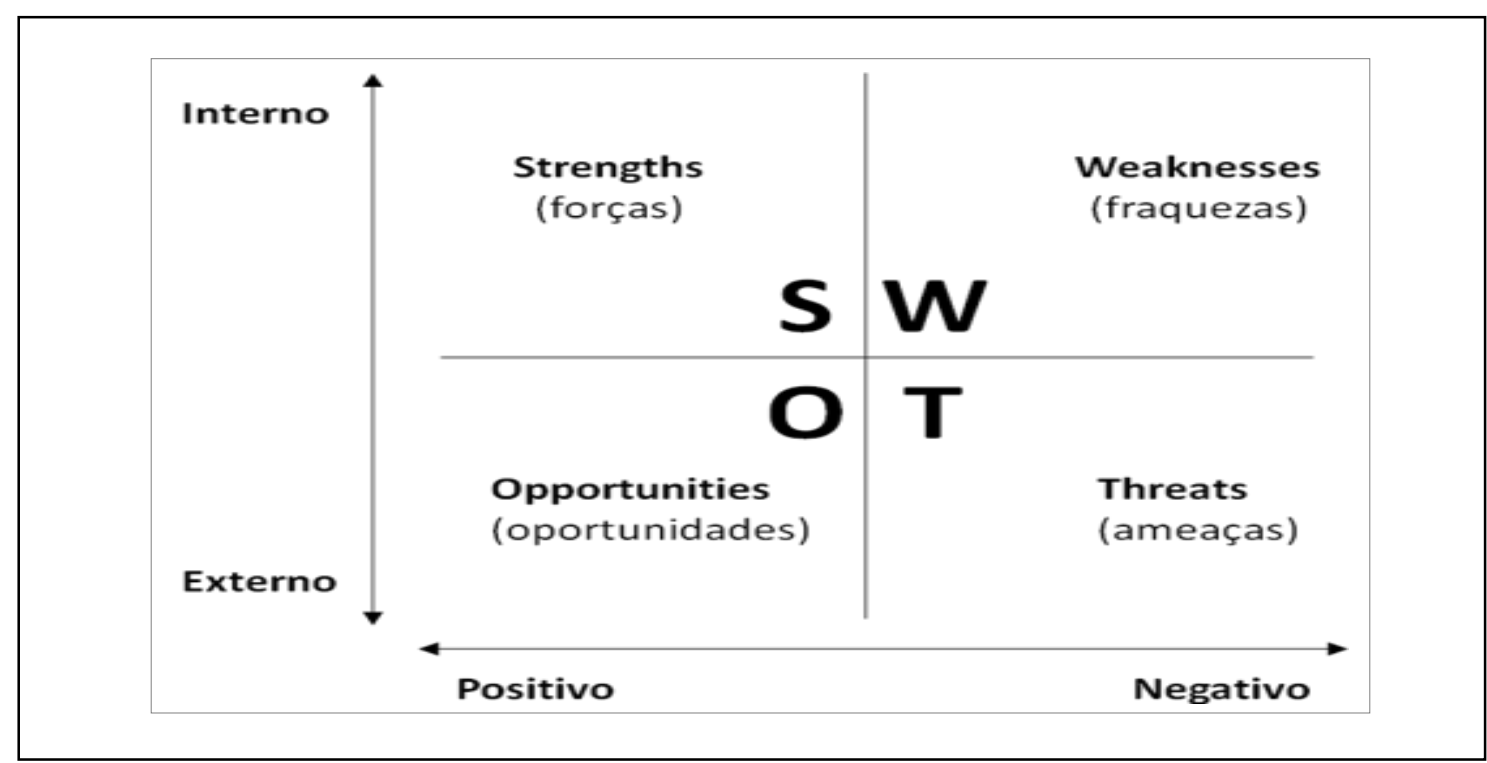

Fonte: Kotler (1998).

De forma geral, a metodologia SWOT busca diagnosticar internamente o setor, por meio da identificação de pontos fortes e fracos, bem como relacionar com o ambiente externo a partir da identificação de ameaças e oportunidades.

\section{Materiais e Métodos}

Esta seção apresentará os aspectos metodológicos desta pesquisa, incluindo a sua classificação, os métodos e as técnicas de pesquisa utilizados, as definições da amostragem utilizada e, ainda, os aspectos metodológicos do diagnóstico, ou seja, a metodologia usada na fase de interpretação e análise dos dados.

Inicialmente, ressalta-se que a pesquisa está classificada como exploratória, pois visa aumentar a aproximação de um determinado fato, constituindo-se de uma primeira etapa de levantamento de dados de um fato ou fenômeno, o que possibilita a realização de uma pesquisa futura mais precisa (MARCONI E LAKATOS, 2010; Gil, 2011).

Como encaminhamento para a fase de coleta de dados, utilizou-se da técnica de pesquisa de campo, baseada em entrevistas semiestruturadas, as quais foram aplicadas com empresas participantes de cada um dos APLs investigados, bem como as suas entidades articuladoras de governança local.

Para definição dos APLs pertencentes à região Sudoeste do Paraná, utilizouse a pesquisa Instituto Paranaense de Desenvolvimento Econômico e Social IPARDES (2006), que caracteriza três APLs: Confecções, Móveis e Software.

As definições para a amostragem de empresas de cada APL basearam-se na técnica de amostragem por tipicidade ou intencional, a qual consiste em selecionar um subgrupo representativo da população com base em informações disponíveis (Gil, 2011).

Em função de operacionalização das entrevistas qualitativas aprofundadas, definiu-se como amostragem de empresas, duas empresas por APL. Como critério 
para definição dessas duas empresas, seguindo a técnica de amostragem por tipicidade, adotou-se o parâmetro de número de funcionários por empresa como fator de homogeneização da amostragem, chegando-se ao seguinte resultado: Segundo dados do Ministério do Trabalho MTE/CAGED (2012), o APL Confecções apresentou 55\% das empresas com número de funcionários entre 10 e 20, o APL Móveis com 60\% das empresas com número de funcionários entre 8 e 15 e o APL Software com $85 \%$ das empresas com número de funcionários entre 8 e 15. A partir desse resultado, optou-se em escolher aleatoriamente duas empresas em cada APL dentro das faixas de número de funcionários que representavam a maioria média. . A figura 2 apresenta a estrutura utilizada para a organização das entrevistas realizadas na pesquisa de campo.

Figura 2. Organograma Metodológico da Pesquisa de Campo (Entrevistas)

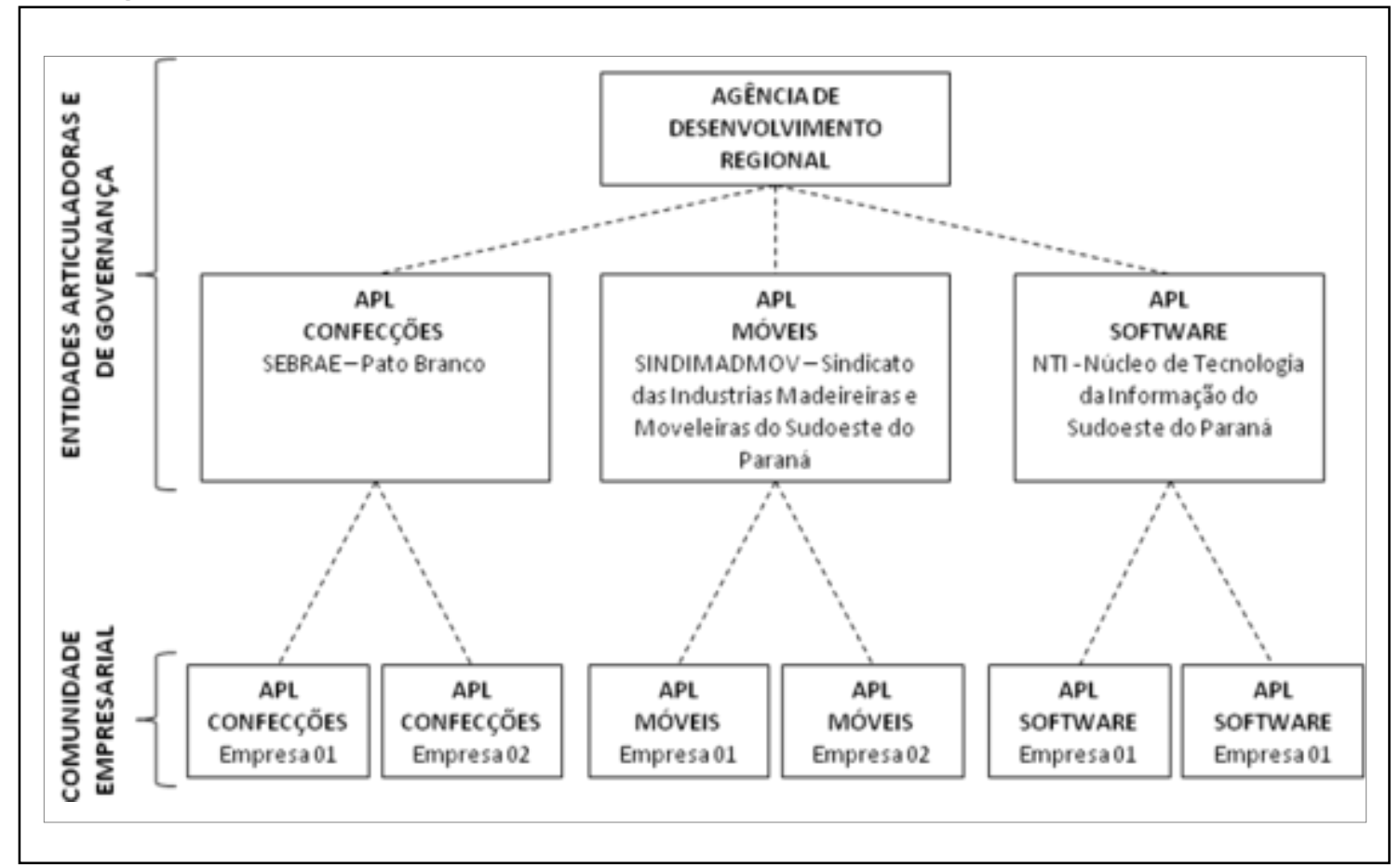

Fonte: Elaboração própria, a partir da pesquisa de campo.

Diante do exposto, a partir dos três arranjos produtivos, respectivamente das atividades econômicas de confecções, móveis e software, foram realizadas seis entrevistas com esta comunidade empresarial (dois empresários por APL), visando diagnosticar aspectos setoriais, a partir do levantamento dos pontos fortes e fracos, oportunidades e ameaças, bem como a visão em relação à governança do APL e à cultura cooperativa do arranjo produtivo.

Ainda em relação à pesquisa de campo, optou-se em entrevistar as entidades articuladoras que representam a governança de cada um desses APLs, além do representante da Agência de Desenvolvimento Regional do Sudoeste do Paraná - ADR. Essas entrevistas buscaram constatar a forma organizativa de cada APL e a condição da infraestrutura regional que são comuns aos arranjos produtivos que foram investigados.

Para o desenvolvimento desse diagnóstico setorial, optou-se pelo método de análise ambiental SWOT, que, apesar de ser utilizado com maior frequência em 
planejamento estratégico de organizações, é adequado para o objetivo proposto por esta pesquisa, uma vez que apresenta uma avaliação bastante detalhada em quatro aspectos de cada APL: pontos fortes, pontos fracos, oportunidades e ameaças.

É importante destacar que a metodologia SWOT é indicada por Johnson e Lundvall (2005) como uma importante ferramenta para o diagnóstico em aglomerações produtivas. Esses autores afirmam que o uso desse conceito gerencial possibilita relacionar as oportunidades e ameaças com o contexto global, enquanto as forças e fraquezas correspondem tanto a aspectos locais quanto as conexões do sistema.

\section{Análise dos Resultados e Discussões}

A partir do principal objetivo estabelecido para a pesquisa, a seção apresenta inicialmente uma breve caracterização do cenário investigado, incluindo informações sobre a região analisada, bem como os referenciais usados na identificação dos arranjos produtivos que foram selecionados para a proposta de discussão. Em seguida, encaminha-se para a análise e as discussões dos resultados encontrados na pesquisa de campo, seguindo a orientação metodológica apresentada na seção anterior.

\subsection{Caracterização do cenário investigado}

A região Sudoeste do Estado do Paraná é formada por 42 municípios em uma área territorial de $16.975 .515 \mathrm{~km} 2$, fazendo fronteira ao sul com o Estado de Santa Catarina e a oeste com a Província de Missiones, pertencente à República da Argentina (AMSOP, 2012). Ademais, considerando a subdivisão geográfica paranaense, corresponde a uma das dez mesorregiões deste estado, incluindo, respectivamente, três microrregiões: Pato Branco, Francisco Beltrão e Capanema, como pode ser visto na área cinza da figura 3.

Em continuidade, ressalta-se que, para a identificação e seleção dos APLs presentes nessa região, optou-se pelas orientações metodológicas usadas no projeto realizado a partir do ano de 2006, o qual foi conduzido pelo IPARDES e pela Secretaria de Estado do Planejamento e Coordenação Geral -SEPL do Estado do Paraná.

Esse projeto buscou a aplicação de instrumentos metodológicos para a identificação e caracterização dos APLs paranaenses. Como principais resultados, foram gerados inúmeros relatórios de apoio para as políticas públicas relacionadas a esse cenário, incluindo um mapeamento geográfico de 22 arranjos produtivos que foram identificados nas 39 microrregiões do Estado do Paraná (IPARDES, 2006). Adicionalmente, a partir da metodologia usada nesse projeto, ressalta-se que estes APLs foram classificados em: NOSR (seis APLs); VOL (quatro APLs); VA (seis APLs); E (seis APLs). A figura 3 apresenta essas informações. 
Figura 3 - Mapa com distribuição geográfica e tipologia dos APLs do Paraná

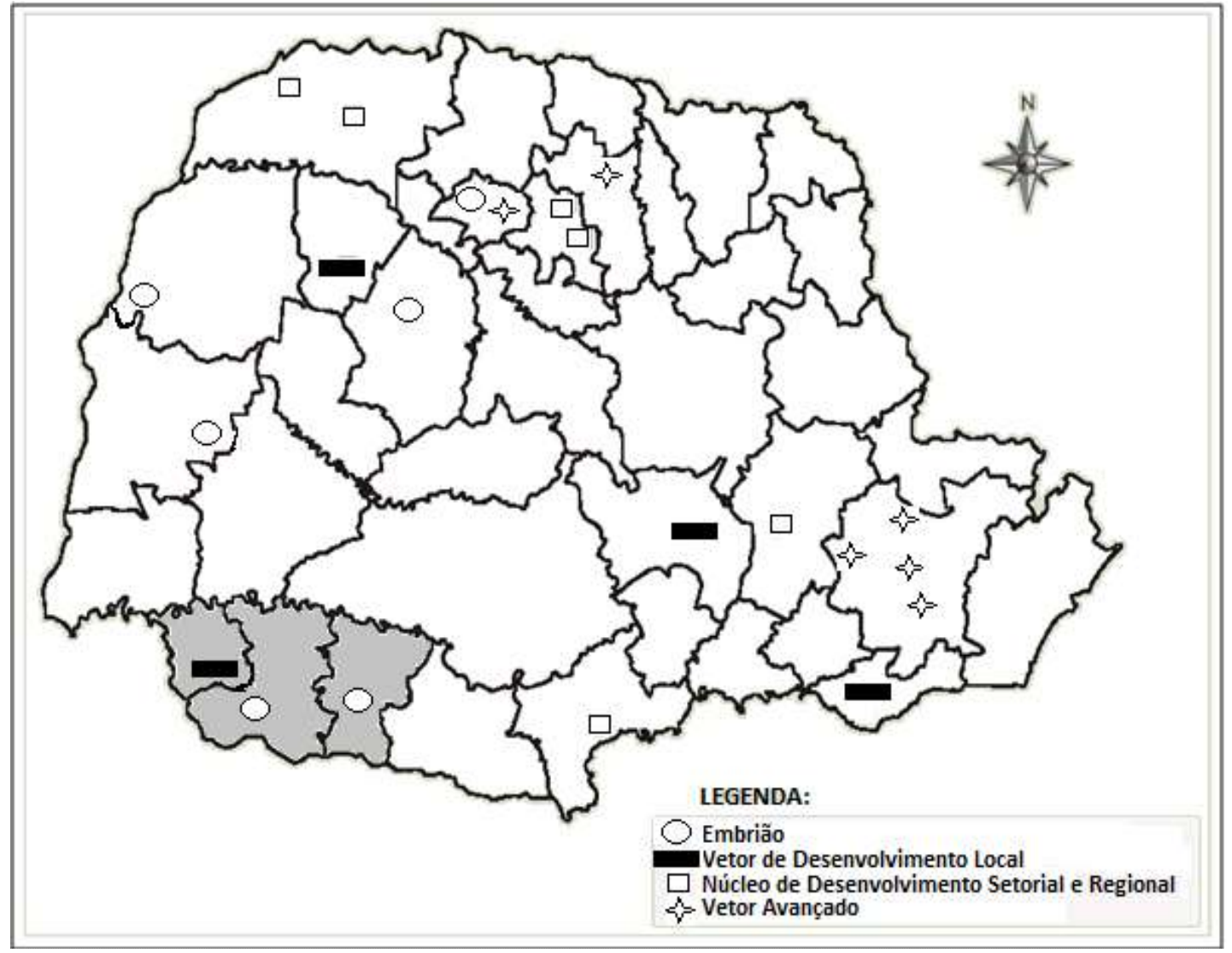

Fonte: Adaptado de IPARDES (2006).

Diante do exposto, foram identificados três arranjos produtivos no Sudoeste do Paraná (área cinza do mapa), correspondendo respectivamente: APL de Confecções (VOL); APL de Móveis (E); APL de Software (E).

Com esse encaminhamento, a próxima subseção apresenta a compilação dos resultados obtidos a partir da pesquisa de campo, com a elaboração de um diagnóstico setorial para estes três arranjos produtivos, bem como a análise e a interpretação destes resultados em relação aos objetivos propostos na pesquisa.

\subsection{Diagnóstico Setorial dos APLs}

Como foi mencionado anteriormente, a orientação metodológica para a realização desse diagnóstico setorial seguiu a metodologia SWOT, com apontamentos nos seguintes quadrantes: Strengths (forças), Weaknesses (fraquezas), Opportunities (oportunidades) e Threats (ameaças). Nessa direção, optou-se em apresentar um único quadro sintético, com um resumo desses apontamentos para cada um dos APLs nesses quadrantes. O quadro 2 apresenta esses resultados. 
Quadro 2. Síntese do Diagnóstico Setorial dos APLs ANÁLISE SETORIAL INTERNA

\begin{tabular}{|c|c|}
\hline \multicolumn{2}{|c|}{ ANÁLISE SETORIAL INTERNA } \\
\hline STRENGTHS (Forças) & WEAKNESSES (Fraquezas) \\
\hline $\begin{array}{l}\text { APL CONFECCÕES } \\
\text { - } \quad \text { Forte cultura associativa no setor; } \\
\text { - } \quad \text { Parcerias público-privadas; } \\
\text { - } \quad \text { APL reconetimento empresarial; } \\
\text { - } \quad \text { Empresas âncoras de médio e grande porte, } \\
\text { - } \quad \text { Atuação da governança do APL; } \\
\text { - Infraestrutura de ensino técnico em escolas } \\
\text { - } \quad \text { Profissionalizantes; } \\
\text { - } \quad \text { matéria-prima; } \\
\text { - Segmento de mercado de alfaiataria masculina. }\end{array}$ & $\begin{array}{l}\text { APL CONFECÇÕES } \\
\text { - } \quad \text { Distâncias dos principais centros consumidores } \\
\text { do Brasil; } \\
\text { - } \quad \text { Distancia dos principais fornecedores de } \\
\text { insumos e matéria-prima; } \\
\text { - } \quad \text { Infraestrutura e logística; } \\
\text { - } \quad \text { Falta de profissionais qualificados em diversos } \\
\text { níveis, com poucos cursos superiores para esta } \\
\text { área; } \\
\text { - Tecnologia usada na indústria local; } \\
\text { - Profissionais formados, especialmente em } \\
\text { cursos básicos de qualificação, sem preparação } \\
\text { - } \quad \text { Segequada para o trabalho; } \\
\quad \text { Segmento de mercado feminino e infantil }\end{array}$ \\
\hline $\begin{array}{l}\text { APL MÓVEIS } \\
\text { - } \quad \text { Investimento em novos produtos; } \\
\text { - } \quad \text { Disponibilidade de matéria-prima; } \\
\text { - } \quad \text { Participação em feiras setoriais; } \\
\text { - } \quad \text { Preocupação com qualidade e acabamento do } \\
\text { - } \text { Maioria das empresas possuem programas de } \\
\text { - } \quad \text { Avaliaçãão positiva da participação em órgãos } \\
\text { coletivos e associativos do setor; } \\
\text { - } \quad \text { Empresas possuem programas de gestão } \\
\text { ambiental; } \\
\text { - } \quad \text { Atendimento das necessidades do consumidor } \\
\text { - } \quad \text { Progional; } \\
\text { insumos; } \\
\text { - Boa remuneração; } \\
\text { - Processo produtivo simples, de fácil } \\
\text { - } \quad \text { Facilidade de treinamento interno para } \\
\quad \text { operações de chão de fábrica. }\end{array}$ & 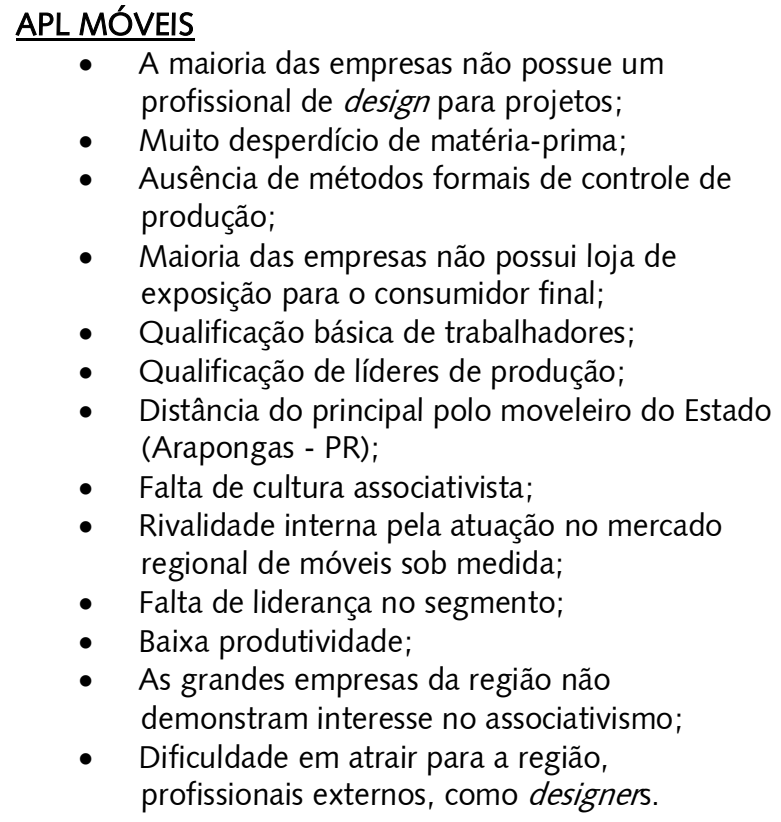 \\
\hline $\begin{array}{l}\text { APL SOFTWARE } \\
\text { - } \quad \text { APL reconhecido em nível federal; } \\
\text { - } \quad \text { cultura associativista ainda é incipiente, mas } \\
\text { - } \quad \text { Governança bem definida e atuante; } \\
\text { - } \quad \text { Atuação da maioria das empresas em nichos } \\
\text { específicos de mercado; } \\
\text { - } \quad \text { Bom relacionamento com outros APLs de } \\
\text { - } \quad \text { Roftware do Estado; } \\
\text { - } \quad \text { público e demais instituições; } \\
\text { - } \quad \text { Reuniões locais nos municípios; } \\
\text { - Profissionais do interior são normalmente mais } \\
\quad \text { comprometidos. }\end{array}$ & $\begin{array}{l}\text { APL SOFTWARE } \\
\text { - Infraestrutura logística, tanto para negócios, } \\
\text { como para implantação dos sistemas (falta de } \\
\text { um aeroporto regional, com linha diária para a } \\
\text { capital); } \\
\text { - Concorrência interna por profissionais; } \\
\text { - Necessidade de qualificação interna dos } \\
\text { - } \text { profissionais recém formados; } \\
\text { Empresas de maior porte têm dificuldade para } \\
\text { realizar um atendimento mais próximos aos } \\
\text { clientes. }\end{array}$ \\
\hline
\end{tabular}




\begin{tabular}{|c|c|}
\hline \multicolumn{2}{|c|}{ ANÁLISE AMBIENTAL EXTERNA } \\
\hline $\begin{array}{l}\text { OPPORTUNITIES } \\
\text { (Oportunidades) }\end{array}$ & $\begin{array}{l}\text { THREATS } \\
\text { (Ameaças) }\end{array}$ \\
\hline 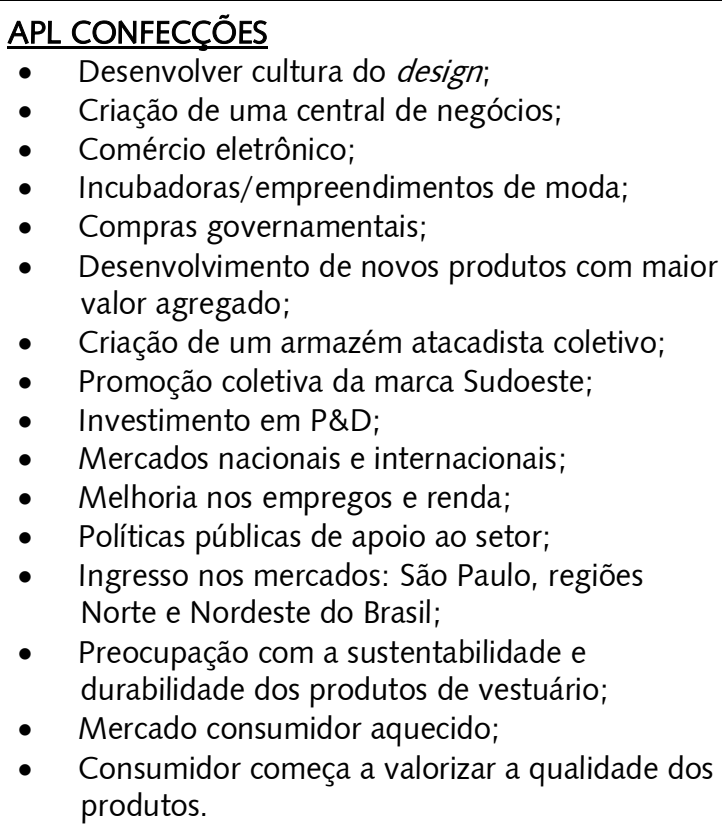 & $\begin{array}{l}\text { APL CONFECÇÕES } \\
\text { - Concorrência internacional nos preços, } \\
\text { especialmente chinesa; } \\
\text { - Apesar da disponibilidade de infraestrutura de } \\
\text { ensino, há uma procura muito baixa pelos } \\
\text { cursos dá área; } \\
\text { - } \quad \text { Falta de atratividade regional para captação de } \\
\text { profissionais de fora da região; } \\
\text { - Carga tributária alta, diminuindo a } \\
\text { competitividade, especialmente perante os } \\
\text { importados; } \\
\text { Baixa remuneração no setor e falta de plano de } \\
\text { carreira para os colaboradores das empresas; } \\
\text { O risco de perda de qualidade com a } \\
\text { terceirização em facções. }\end{array}$ \\
\hline $\begin{array}{l}\text { APL MÓVEIS } \\
\text { - } \quad \text { Rede informal de comunicação; } \\
\text { - } \quad \text { Início de reuniões para governança local; } \\
\text { - } \quad \text { gerelas volantes do setor moveleiro, } \\
\text { - Mudanças rápidas no comportamento do } \\
\text { consumidor de móveis; } \\
\text { - Copa do mundo de futebol em } 2014 \text { e os jogos } \\
\quad \text { olímpicos do Rio de Janeiro de 2016, } \\
\text { principalmente para moveis direcionados a rede } \\
\text { hoteleira e restaurantes; } \\
\text { Segmento de produção seriada, com mercado } \\
\text { mais amplo. }\end{array}$ & $\begin{array}{l}\text { APL MÓVEIS } \\
\text { - } \quad \text { Falta de profissionais de design; } \\
\text { - } \quad \text { Carência de escolas técnicas específicas para } \\
\text { - } \quad \text { Falta atividade econômica; } \\
\text { - dificuldade na área de marcenaria; } \\
\text { - } \quad \text { Pessoas têm apresentado resistência para } \\
\text { - } \quad \text { Mercado regiononal de móveis sob medida é } \\
\text { - } \quad \text { Asmitado; exportações são baseadas em preço e } \\
\text { dependentes de oscilação cambial. }\end{array}$ \\
\hline 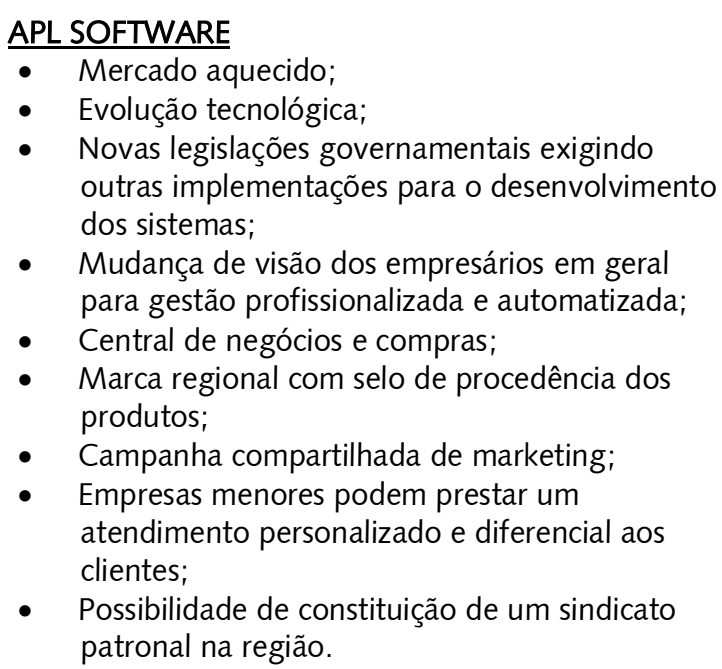 & $\begin{array}{l}\text { APL SOFTWARE } \\
\text { - } \quad \text { Formação insuficiente de mão de obra na } \\
\text { região; } \\
\text { - } \quad \text { Evasão de profissionais, principalmente para } \\
\text { grandes centros; } \\
\text { - } \quad \text { Por falta de mão de obra, muitas empresas } \\
\text { estão transferindo unidades para outros } \\
\text { centros, com maior disponibilidade de } \\
\text { profissionais; } \\
\text { - Dificuldade em atrair profissionais para o } \\
\text { interior; } \\
\text { - Grandes centros remuneram melhor os } \\
\text { - } \quad \text { Erofissionais da área de tecnologia; } \\
\text { Entrada não vocacionada nos cursos de } \\
\text { graduação; } \\
\text { Profissionais de programação têm migrado para } \\
\text { atividades comerciais. }\end{array}$ \\
\hline
\end{tabular}

Fonte: Elaboração própria, a partir da pesquisa de campo. 
Como pode ser visto no quadro 2, a metodologia SWOT representa uma importante ferramenta para a análise do cenário de aglomerações produtivas (JOHNSON E LUNDVALL, 2005). Os dados apresentados neste quadro sintético (quadro 2) possibilitam uma análise individual em cada um dos quadrantes SWOT, revelando assim, especificidades pontuais de um determinado arranjo produtivo. Como exemplo, o nicho de atuação do APL de Confecções no mercado de alfaiataria masculina, ou ainda, a oportunidade de constituição regional de um sindicato patronal para a atividade de software.

Contudo, ressalta-se o principal objetivo desta pesquisa visa não somente orientar a elaboração de estratégias para o desenvolvimento desses APLs, mas também contribuir na definição de estratégias para o desenvolvimento regional. Nesse sentido, entende-se que um apontamento específico de um $A P L$, não necessariamente, representa elementos para uma análise contextualizada de indicadores daquela região.

Como encaminhamento, optou-se em realizar uma compilação mais integrada e sistêmica desses dados a partir de um recorte metodológico baseado em uma análise qualitativa, a qual considerou exclusivamente aqueles apontamentos que foram mencionados em pelo menos dois APLs investigados, logicamente, sempre em relação ao mesmo quadrante de análise.

Por conseguinte, obteve-se uma representação gráfica desses apontamentos nos respectivos quadrantes: Strengths (forças), Weaknesses (fraquezas), Opportunities (oportunidades) e Threats (ameaças). A síntese desses resultados pode ser vista na figura 4, a qual possibilitará a orientação metodológica para os encaminhamentos referentes à análise e às discussões propostas para este artigo.

Nesse sentido, a partir da síntese apresentada na figura 4, encaminha-se para uma análise pautada pela visão estratégica das possibilidades e limites para o desenvolvimento regional do cenário investigado. Com esse propósito, inicialmente serão analisados os apontamentos positivos, os quais estão situados no lado esquerdo da figura 4, representados pela identificação das forças e oportunidades. Em seguida, encaminha-se para os pontos negativos, representados pelas fraquezas e ameaças. 
Figura 4 - Síntese integrada dos resultados da compilação SWOT

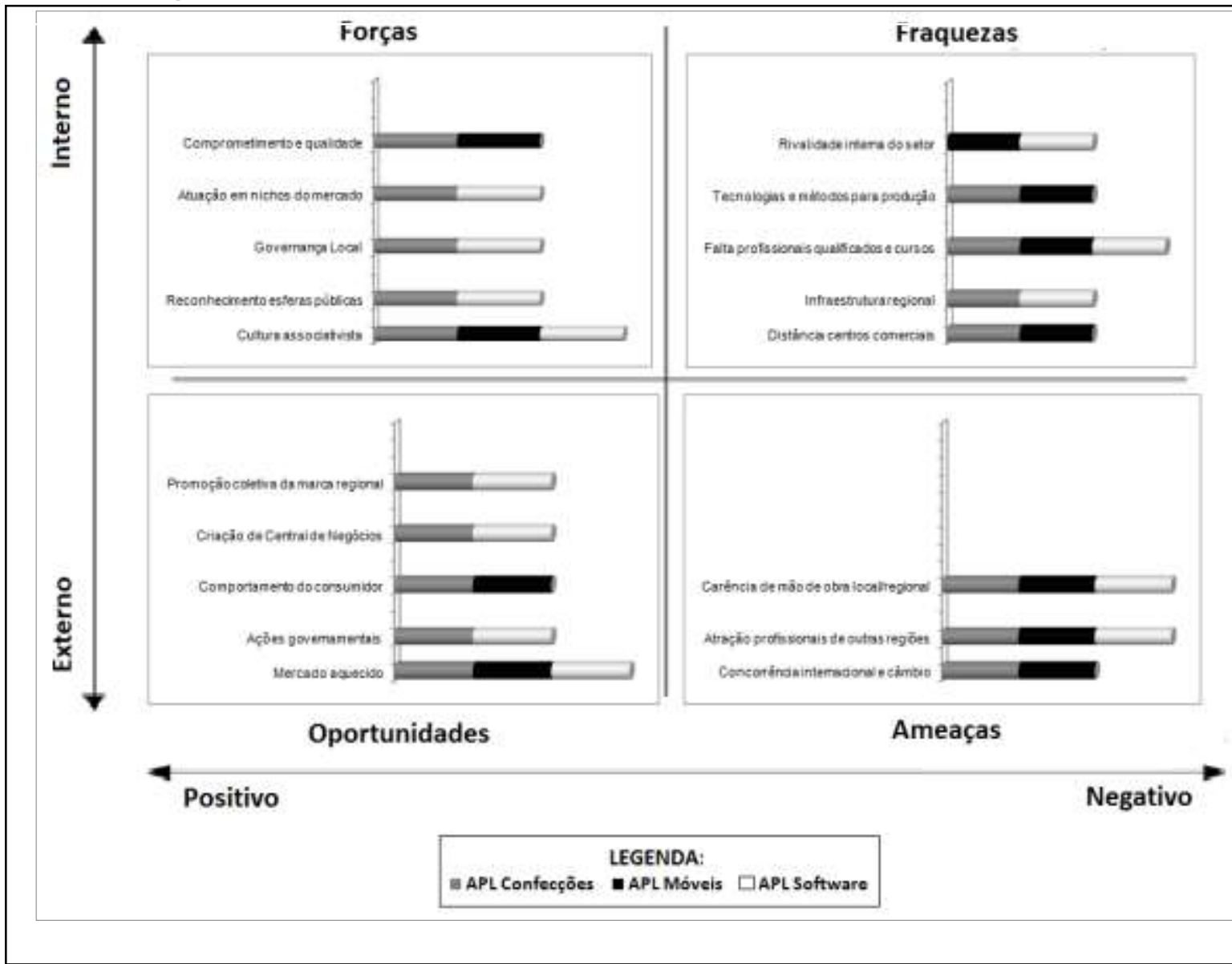

Fonte: Elaboração própria, a partir da pesquisa de campo.

Um dos pontos fortes identificados na pesquisa refere-se à cultura associativista dos participantes desses APLs, a qual está presente nos três arranjos analisados, a partir da promoção de algumas ações cooperativas, como exemplos: treinamentos, missões comerciais e participações em feiras comerciais. Nesse sentido, Schmitz (1997) afirma que as empresas organizadas em aglomerações produtivas (clusters ou APLs) necessitam de ações conjuntas, as quais possibilitam ganhos e competitividade de forma coletiva. Corroborando com esse debate, Amato Neto (2009) aponta que essas ações cooperadas representam uma evolução no processo cooperativo e são importantes para a maturidade de um APL.

Nessa direção, revela-se também a importância da governança local do arranjo produtivo, a qual se caracteriza pelo estabelecimento de práticas democráticas locais por meio da intervenção e participação de diferentes categorias de atores nos processos de decisão locais (CASSIOLATO E SZAPIRO, 2003). No cenário investigado, a governança local foi mencionada como um ponto forte em dois APLs (APL Confecções e APL Software), revelando uma condição favorável para o desenvolvimento desses arranjos produtivos e da respectiva região.

Outro ponto forte encontrado na pesquisa de campo é o reconhecimento das esferas públicas em relação a dois APLs (confecções e software), pois a 
literatura aponta que a intervenção do Estado é essencial para o desenvolvimento produtivo local. De forma geral, o Estado deve promover a construção de forças centrípetas, buscando sempre a melhoria das condições locais, as quais possibilitem o crescimento das empresas e o aumento do emprego e da renda local (SUZIGAN, 2006; COSTA, 2010).

Ainda na análise dos pontos positivos, o quadrante das oportunidades revela que as ações governamentais estão presentes nesses mesmos dois APLs (confecções e software) que são reconhecidos pelo poder público. Nessas discussões, é fundamental observar a necessidade de uma maior mobilização dos participantes do APL de Móveis, pois poderá gerar um ambiente sistêmico que é essencial como elemento sinérgico para as relações das políticas públicas com as questões territoriais (ALBUQUERQUE, 1998; BENKO, 1999).

Outra oportunidade identificada refere-se à percepção sobre o aquecimento do mercado, mencionado nos três APLs investigados (confecções, móveis e software). De forma geral, é importante destacar que essa oportunidade deriva de condições externas, como exemplo, a atual estabilidade econômica brasileira e a expansão do mercado consumidor interno. Contudo, essa oportunidade de expansão, principalmente para São Paulo e a região Nordeste do Brasil, pode ser limitada, inclusive pelas condições macroeconômicas nacionais e internacionais (importações).

Nessas discussões, uma alternativa interessante é mencionada por Suzigan et al. (2004), referindo-se às estratégias de inteligência comercial e desenvolvimento de canais de distribuição e acesso a novos mercados. Com esse propósito, identificou-se que o APL de Confecções e o APL de Software estão visualizando essa oportunidade a partir da promoção coletiva da marca regional de seus produtos, o que demonstra um aspecto muito importante para o fortalecimento dessas atividades econômicas na região Sudoeste do Paraná. Além disso, esses dois arranjos produtivos também indicaram para a canalização dos esforços coletivos em direção à criação de uma central de negócios, o que permitiria uma maior visibilidade e oportunidade comercial.

Em contrapartida, a aplicação da metodologia SWOT revelou alguns pontos negativos, os quais podem dificultar a expansão e o nível de contribuição dessas atividades econômicas para o desenvolvimento regional. A compilação desses dados pode ser vista nos quadrantes situados no lado direito da figura 4, representados pelos apontamentos referentes às fraquezas e ameaças.

Como foi mencionado na fundamentação teórica, uma característica importante e necessária para a existência de um APL é a existência de vínculos e interação entre os agentes participantes, o que propicia ganhos de eficiência coletiva gerados pelas ações conjuntas (SCHMITZ, 1997). Contudo, obviamente sempre existirão relações de competitividade dentro da aglomeração produtiva, mas estas não devem influenciar negativamente nas ações coletivas, ao contrário, devem estar em um nível que possibilite estimular a competitividade, chamada de rivalidade positiva (PORTER, 1998).

Corroborando com essas discussões, Villela e Pinto (2009) afirmam que um dos grandes problemas da gestão de um arranjo produtivo é a desconfiança gerada pela concorrência predatória entre as empresas. Como pode ser visto no quadrante das fraquezas na figura 4, o APL de Móveis e o APL de Software apontaram para a existência de altos níveis de rivalidade interna em seus 
respectivos setores. Essa concorrência interna é gerada, em grande, parte pela atuação no mesmo segmento comercial em nível regional, ocasionando o acirramento na disputa por clientes. É importante destacar que uma forte rivalidade interna é diferente da rivalidade positiva defendida por Michael Porter, a qual estimula a competitividade por meio da inovação (PORTER, 1998).

Ainda nesse debate, é importante observar que a existência de uma aglomeração produtiva forte e consistente deve propiciar a geração das chamadas externalidades marshallianas, entre as quais, mão de obra qualificada para a atividade econômica e o maior acesso aos fornecedores e mercados (MARSHALL, 1982). Contudo, os três arranjos produtivos indicaram que essas condições são negativas naquela região, pois faltam profissionais qualificados e cursos para a atividade econômica. Ademais, a infraestrutura regional e o acesso aos principais centros comerciais também foram indicados como fraquezas para o desenvolvimento das atividades econômicas das empresas participantes desses APLs.

Em continuidade na análise dos pontos negativos que foram identificados na pesquisa de campo, o quadrante das ameaças também indica uma grande preocupação com a mão de obra regional, incluindo, ainda, o problema da dificuldade de atração de profissionais de outras regiões, muitas vezes, limitada pelas condições locais ou pelas políticas salariais praticadas pelas empresas desses arranjos produtivos.

Em síntese, as entrevistas revelaram que a região dispõe de um volume insuficiente de mão de obra específica para essas atividades econômicas, o que pode ainda se agravar com o risco em perder bons profissionais para outras regiões do país, devido ao próprio aquecimento do mercado econômico nacional.

Outra ameaça refere-se à exportação, que geralmente é considerada uma ótima oportunidade para as empresas, porém, nesses APLs, corresponde a uma ameaça, justamente pela modalidade com que tem sido conduzida por muitas dessas empresas, que negociam seus produtos como commodities, em uma acirrada competição focada exclusivamente no preço.

É necessário destacar que essa condição representa alto risco para essas atividades econômicas em função da vulnerabilidade em relação à competitividade internacional de baixo custo e as oscilações cambiais. Nesse sentido, a literatura aponta para o risco da simples integração em redes de exportação de commoditties, quando o foco do arranjo produtivo deveria ser o aumento da produtividade, eficiência e inovação (PORTER, 1998; CASSIOLATO e SZAPIRO, 2003).

\section{Considerações Finais}

A literatura aponta para alguns fatores como principais responsáveis pela valorização da concentração especial de pequenas e médias empresas em aglomerações produtivas locais ou regionais, destacando-se entre estes, a mudança ocorrida nas duas últimas décadas do século $X X$ no padrão de acumulação do sistema capitalista, a partir da substituição do modelo fordista/taylorista pelo regime de acumulação flexível. 
Nesse cenário, estão inseridos os APLs, como uma forma de organização espacial para a mobilização e a cooperação dos agentes territoriais, implicando, assim, nas condições de desenvolvimento local ou regional. Cabe destacar que esse movimento tem encontrado sinergia nas políticas públicas relacionadas às questões do desenvolvimento regional.

Diante do exposto, esta pesquisa buscou realizar um diagnóstico setorial dos APLs existentes na região Sudoeste do Paraná, visando orientar a elaboração de estratégias de desenvolvimento, tanto para esses APLs como para a própria região. Com esse propósito, a investigação foi conduzida pela aplicação da metodologia SWOT, possibilitando diagnosticar internamente o setor (forças e fraquezas), bem como os possíveis relacionamentos com o ambiente externo (oportunidades e ameaças), a partir de entrevistas realizadas com agentes dos três APLs selecionados: APL de Confecções; APL de Móveis; APL de Software.

A compilação dos apontamentos da pesquisa de campo gerou um conjunto de aspectos positivos (forças e oportunidades), bem como negativos (fraquezas e ameaças) em relação a estas atividades econômicas organizadas nesses três APLs, possibilitando, assim, a análise dos possíveis impactos (limites e possibilidades) para o desenvolvimento da respectiva região.

Como principais resultados, destacam-se positivamente: a presença da cultura associativista nos três APLs; a representatividade da governança local e o reconhecimento das esferas públicas (APL de Confecções e APL de Software); iniciativas para a criação de Central de Negócios e a promoção coletiva da marca regional (APL de Confecções e APL de Software); entre outros aspectos identificados na pesquisa.

Em contrapartida, alguns apontamentos demonstraram uma significativa fragilidade desses arranjos produtivos em áreas estratégicas para o desenvolvimento setorial e regional, podendo ser citados entre os principais pontos negativos: altos níveis de rivalidade interna das empresas do setor (APL de Móveis e APL de Software); carência de profissionais qualificados e insuficiente infraestrutura regional para as atividades dos três APLs; concorrência internacional e oscilações cambiais (APL de Confecções e APL de Móveis).

Em relação à contribuição desses três APLs ao desenvolvimento regional, pode-se concluir que são os setores econômicos que demonstram, até o momento, o maior nível de organização em termos cooperativos e de planejamento setorial, fator de extrema importância para que possam se beneficiar de políticas públicas, como na área de educação profissional, por exemplo, carência para todos os APLs, como apontado na pesquisa. Outro aspecto de relevância dos APLs abordados na pesquisa é que, conforme definição de amostragem realizada, os três setores apresentam predominância de empresas de pequeno e médio porte, representando, de forma geral, a característica das indústrias regionais.

A pesquisa apontou também mercado aquecido para os três setores, ou seja, oportunidade de expansão e crescimento, proporcionando geração de emprego e renda de forma qualitativa, por meio de desenvolvimento de produtos e marcas exclusivas de maior valor agregado. Esse crescimento qualitativo poderá, inclusive, contribuir no combate a uma das ameaças, que é a evasão de profissionais para outras regiões, uma vez que um ambiente profissional de criação e desenvolvimento poderá estimular a permanência na região dos melhores profissionais. A outra grande deficiência apontada pela pesquisa foi a questão de 
qualificação de mão de obra, mas que pode ser trabalhada, uma vez que a região possui uma boa institucionalidade de educação profissional, necessitando, talvez, de um maior diálogo com o setor produtivo para harmonizarem as estratégias de formação e demanda.

Em síntese, é possível afirmar que esta pesquisa atingiu os objetivos propostos, com a elaboração de um diagnóstico setorial que poderá orientar na elaboração de políticas públicas e estratégias para o desenvolvimento regional. Ademais, encaminha-se como sugestão de trabalhos futuros um aprofundamento dessas discussões visando à identificação das possíveis causas e consequências de cada um dos apontamentos específicos que foram apresentados neste artigo.

\section{REFERÊNCIAS}

ALBUQUERQUE, F. Desenvolvimento econômico local e distribuição do progresso técnico: uma resposta às exigências do ajuste estrutural. Fortaleza: BNB, 1998.

AMSOP. Associação dos Municípios do Sudoeste do Paraná. Banco de Dados do Sudoeste do Paraná. Disponível em: <http://www.amsop.com.br> Acesso em: 15 ago. 2012.

BECATTINI, G. O Distrito Marshalliano. In: BENKO, G. \& LIPIETZ, A. (org.). As Regiões Ganhadoras- Distritos e Redes: os novos paradigmas da geografia econômica. Celta editores: 1994

BENKO, Georges. Economia, espaço e globalização: na aurora do século XXI. Tradução: Antonio de Pádua Danesi. 2. ed. São Paulo: Hucitec, 1999.

CASSIOLATO, J.E.; SZAPIRO M. Uma Caracterização de Arranjos Produtivos Locais de Micro e Pequenas Empresas. In: LASTRES, H.M.M.; CASSIOLATO, J.E.; MACIEL, M.L. (org). Pequena Empresa: Cooperação e Desenvolvimento Local. Rio de Janeiro: Relume Dumerá, UFRJ, Instituto de Economia, 2003.

CERTO, S.C.; PETER, J.P. Administração Estratégica: Planejamento e Implantação de Estratégias. São Paulo: Pearson Education do Brasil, 2010.

COSTA, E. J. M. Arranjos Produtivos Locais, Políticas Públicas e Desenvolvimento Regional. Brasília: Mais gráfica editora, 2010.

COSTA, E. J. M. da. Arranjos Produtivos Locais, Políticas Públicas e Desenvolvimento Regional. Brasília: Mais Gráfica Editora, 2010.

DIAS, G. N. Arranjos Produtivos Locais (APLs) como Estratégia de Desenvolvimento. Revista Desenvolvimento em Questão, ano. 9, $\mathrm{n}^{\circ}$ 17, janeirojunho/2011. 
FREEMAN, C. Um Pouso Forçado para a "Nova Economia"? A Tecnologia da Informação e o Sistema Nacional de Inovação dos Estados Unidos. In: LASTRES, H.M.M.; CASSIOLATO, J.E.; ARROIO, A (org). Arranjos Produtivos Locais: Uma Alternativa para o Desenvolvimento, Rio de Janeiro: Editora UFRJ - Contraponto, 2005.

FRIESNER, T. History of SWOT Analysis. 2014. Disponível em:

<http://www.marketingteacher.com/history-of-swot-analysis/>. Acesso em: 24 mar 2016.

GARCIA, J.R.; COSTA, A.J.D.; Sistemas Produtivos Locais: Uma Revisão de Literatura. In II Seminário de Gestão de Negócios. Curitiba, 2005.

GIL, A.C. Método e Técnicas de Pesquisa Social. 6 ed. São Paulo: Atlas, 2011.

IPARDES - Instituto Paranaense de Desenvolvimento Econômico e Social. Identificação, caracterização, construção de tipologia e apoio na formulação de políticas para os arranjos produtivos locais (APLS) do Estado do Paraná: Diretrizes para políticas de apoio aos arranjos produtivos locais. Instituto Paranaense de Desenvolvimento Econômico e Social, Secretaria de Estado do Planejamento e Coordenação Geral. Curitiba: IPARDES, 2006.

JOHNSON, B.; LUNDVALL, B.A. Promovendo Sistemas de Inovação como Resposta a Economia do Aprendizado Crescentemente Globalizada. In: LASTRES, H.M.M.; CASSIOLATO, J.E.; ARROIO, A (org). Arranjos Produtivos Locais: Uma Alternativa para o Desenvolvimento, Rio de Janeiro: Editora UFRJ - Contraponto, 2005.

KAPLAN, R.S.; NORTON, D. P. A Estratégia em Ação: Balanced Scorecard. Rio de Janeiro: Campus, 1997.

KOTLER, P.; ARMSTRONG, G. Princípios de Marketing. Prentice Hall - Brasil, 1998.

LASTRES,H.M.M.; CASSIOLATO, J.E. O Foco em Arranjos Produtivos e Inovativos Locais de Micro e Pequenas Empresas. In: LASTRES, H.M.M.; CASSIOLATO, J.E.; MACIEL, M.L. (org). Pequena Empresa: Cooperação e Desenvolvimento Local. Rio de Janeiro: Relume Dumará, UFRJ, Instituto de Economia, 2003.

LASTRES,H.M.M.; CASSIOLATO, J.E.; ARROIO, A. Conhecimento, Sistemas de Inovação e Desenvolvimento. Rio de Janeiro: Editora UFRJ - Contraponto, 2005.

MARCONI, M.A.; LAKATOS, E.M. Fundamentos de Metodologia Científica. 7 ed. São Paulo: Atlas, 2010.

MARINI, M. J.; SILVA, C.L. Desenvolvimento Regional e Arranjos Produtivos Locais: uma abordagem sob a ótica interdisicplinar. Revista Brasileira de Gestão e Desenvolvimento Regional (G\&DR), vol. 8, $\mathrm{n}^{\circ} 2$, p. 107-129, maio-agosto/2012. 
MARSHALL, A. Princípios de Economia: tratado introdutório. São Paulo: Abril Cultural, 1982. (Série: Os Economistas; Primeira edição: 1890).

MINISTÉRIO DO TRABALHO E EMPREGO - Cadastro Geral de Empregados e Desempregados (CAGED). Perfil do Município. Disponível em:

$<$ http://bi.mte.gov.br/bgcaged/caged_perfil_municipio/index.php $>$. Acesso em: 03 jul. 2012.

MINTZBERG, H.; QUINN, J.B. O Processo da Estratégia. Porto Alegre: Bookman, 2001.

NETO, J. A. Gestão de Sistemas Locais de Produção e Inovação (Clusters/APL 's). São Paulo: Atlas, 2009.

PORTER, M. E. Clusters and the New Economics of Competition. Harvard Business Review, Nov/Dec 1998.

PORTER, M. E. Competição. Rio de Janeiro: Elsevier, 2009.

SCHMITZ, H. Collective efficiency and increasing returns. In: IDS Working Paper 50, Bringhton: Institute of Development Studies, University of Sussex, March 1997.

SUZIGAN, W.; FURTADO, J.; GARCIA, R.; SAMPAIO, S. Clusters ou Sistemas Locais de Produção: Mapeamento, Tipologia e Sugestões de Políticas. Revista de Economia Política, vol. 24, nº 4 (96), outubro-dezembro/2004.

SUZIGAN. W. (Coord.). Identificação, mapeamento e caracterização estrutural de arranjos produtivos locais no Brasil. Brasília: IPEA/DISET, Relatório Consolidado, 2006.

TEIXEIRA, F. Políticas Públicas para o desenvolvimento Regional e Local: o que podemos apreender com os arranjos produtivos locais. Revista $O \& S$, vol. 15, n 46, julho-setembro, 2008.

VILLELA, L. E.; PINTO, M. C. S. Governança e gestão social em redes empresariais: análise de três arranjos produtivos locais (APLs) de confecções no estado do Rio de Janeiro. Revista de Administração Pública, Rio de Janeiro, v. 43, n. 5, p. 10671089, set./out., 2009. 


\section{Sobre os autores}

\section{Alexandre Luiz Schlemper}

Mestre em Desenvolvimento Regional (PPGDR). Professor do Instituto Federal do Paraná (IFPR) Câmpus Palmas.

Endereço para correspondência: Av. Bento Munhoz da Rocha Neto s/n - PRT-280. 85.555-000

Palmas - Paraná - Brasil.

E-mail: alexandre.schlemper@ifpr.edu.br

\section{Marcos Junior Marini}

Doutor em Tecnologia / Desenvolvimento Regional. Professor da Universidade Tecnológica Federal do Paraná (UTFPR)/Câmpus Pato Branco/Programa de Pós Graduação em Desenvolvimento Regional - PPGDR.

Endereço para correspondência: Via do Conhecimento, Km 1. 85.503-390 - Pato Branco - Paraná Brasil

E-mail: marini@utfpr.edu.br

\section{Maria de Lourdes Bernartt}

Doutora em Educação (UNICAMP). Professora da Universidade Tecnológica Federal do Paraná (UTFPR)- Câmpus Pato Branco. Programa de Pós Graduação em Desenvolvimento Regional (PPGDR).

Endereço para correspondência: Via do Conhecimento, Km 1. 85.503-390 - Pato Branco - PR Brasil

E-mail marial@utfpr.edu.br 